\title{
Covid-19 Salgın Döneminde Sınıf Öğretmenlerinin Hayat Bilgisi Dersi Öğretimine Yönelik Görüşleri
}

\author{
Onur BATMAZ1 ${ }^{1}$ Meltem CEVAHIR BATMAZ² ve Ahmet KILIÇ33
}

$\ddot{O} z$

Bu araştırmada, Covid-19 salgın döneminde sınıf öğretmenlerinin Hayat Bilgisi dersi öğretimine yönelik görüşlerinin incelenmesi amaçlanmıştır. Nitel araştırma yöntemlerinden durum çalışmasında yürütülen bu çalışmanın katılımcıları, ölçüt örnekleme ile belirlenen Yozgat ilinde görev yapan 19 sınıf öğretmeninden oluşmaktadır. Çalışmanın verilerinin toplanmasında yarı yapılandırılmış görüşme formu kullanılmıştır. Elde edilen bulgular, betimsel analizle elde edilmiştir. Çalışma sonucunda ise, Covid-19 salgın dönemi Hayat Bilgisi dersi öğretiminde öğretmenlerin materyal olarak daha çok ders kitabı, video ve animasyonları kullandıkları, ölçme değerlendirmede ise daha çok soru-cevap ile ders kitabı etkinliklerinden yararlandıkları görülmüştür. Öğretmenlerin tamamı bu salgın döneminde Hayat Bilgisi dersinin öneminin arttığını düşünmektedir. Öğretmenlerin bu süreçte Hayat Bilgisi dersi öğretimine yönelik birçok sorunla karşılaştıkları ama en fazla internet erişim olanaklarının yetersiz olması ile somut materyalleri kullanamama sorunlarıyla karşılaştıkları bulunmuştur. Covid-19 salgın dönemi uzaktan eğitim sürecinde öğretmenlerin önemli bir kısmı Hayat Bilgisi dersini EBA TV'den takip etmesine rağmen verimli bulmadıklarını ifade etmişlerdir. Öğretmenlerin büyük bir kısmının ise EBA platformunu kullandıkları sonucuna ulaşılmıştır. Ayrıca öğretmenlerin önemli bir kısmı Hayat Bilgisi kazanımlarının olağanüstü durumlara göre yenilenmesi ve salgınlara yönelik kazanımların eklenmesine yönelik görüş belirtmişlerdir.

Anabtar Kelimeler: Covid-19, Hayat Bilgisi, Öğretim, Salgın

Opinions of Primary School Teachers about Life Science Course Teaching During The Covid-19 Epidemic

\begin{abstract}
In this study, it was aimed to examine the opinions of primary school teachers about the Life Studies course teaching during the Covid-19 epidemic period. Participants of this study, which is carried out in the case study, one of the qualitative research methods, consist of 19 primary school teachers working in the city of Yozgat, whose criteria were sampled. A semi-structured interview form was used to collect the data of the study. Descriptive analysis technique was used to analyze the data obtained. As a result of the study, it was seen that teachers used more textbooks, videos and animations as materials in the Life Science course teaching of the Covid-19 epidemic period, and they used more questions and answers and textbook activities in assessment and evaluation. All of the teachers think that the importance of the Life Studies course has increased during this epidemic period. In this process, it was found that teachers faced many problems related to the Life Studies course teaching, but mostly they faced with inadequate internet access facilities and inability to use concrete materials. They stated that although they followed the Life Studies course on EBA TV, they did not find it efficient. It was concluded that most of the teachers used the EBA platform. In addition, a significant part of the teachers expressed their opinions on the renewal of Life Science achievements according to extraordinary situations and the addition of acquisitions related to epidemics.
\end{abstract}

Key Words: Covid-19, Life Science, Teaching, Epidemic

Atıf İçin / Please Cite As:

Batmaz, O., Cevahir Batmaz, M. ve Kılıç, A. (2021). Covid-19 Salgın Döneminde Sınıf Öğretmenlerinin Hayat Bilgisi Dersi Öğretimine Yönelik Görüşleri. Manas Sosyal Araştırmalar Dergisi, 10(3), 1665-1677.

Geliş Tarihi / Received Date: 21.12.2020

Kabul Tarihi / Accepted Date: 01.04.2021

\footnotetext{
${ }^{1}$ Öğr. Gör. - Yozgat Bozok Üniversitesi Sağlık Hizmetleri Meslek Yüksekokulu, onur.batmaz@yobu.edu.tr

(iD ORCID: 0000-0001-9208-2645

2 Öğretmen - Milli Eğitim Bakanlı̆̆ Şehit Adnan Menderes Gülbaş İlkokulu, meltemcb6161@gmail.com

iD ORCID: 0000-0002-4208-6936

3 Öğr. Gör. - Yozgat Bozok Üniversitesi Sağlık Hizmetleri Meslek Yüksekokulu, ahmet.kilic@yobu.edu.tr

(iD) ORCID: 0000-0001-7147-8552
} 


\section{Giriş}

Dünya var olduğundan bu zamana kadar insanlar belirli dönemlerde bazı felaketlerle mücadele etmek durumunda kalmıştır. Bu felaketler kendini bazen bir savaş, bir doğal afet, bulaşıcı bir hastalık olarak göstermiştir. Günümüzde de bu felaket, bir salgin olarak ortaya çıkmış tüm dünyayı etkisi altına almıştır. Türk Dil Kurumu'na (2019) göre salgın, "bir hastalığın veya başka bir durumun yaygınlaşması ve birçok kimseye birden bulaşması" olarak tanımlanmaktadır. Geçmişten günümüze kadar veba, kolera, İspanyol gribi, SARS, domuz gribi gibi birçok salgın görülmüştür. 2019 Aralık ayında Çin’in Wuhan kentinde ortaya çıkan Yeni Tip Koronavirüs (Covid-19) kısa bir zamanda tüm dünyaya yayılmış ve Dünya Sağlık Örgütü (WHO, 2020) tarafından bir salgın olarak adlandırılmışıtır. Hızla dünyaya yayılan bu salgının ülkemizdeki ilk vakas1 11 Mart 2020'de görülmüştür (Sağlık Bakanlığı, 2020, s. 2). İlk vakanın görüldüğü tarih itibariyle sağlık başta olmak üzere eğitim, ekonomi, turizm, ulaşım, iş hayatı ve sosyal etkinlikler gibi alanlarda önemli değişiklikler ortaya çıkmışır. İnsanların bu alanlarda ortaya çıkan değişiklikleri kabullenmesinin kolay olmadığı ve bu durumunda insanlarda stres, korku, endişe, kayg1 yarattığ1 düşünülmektedir. Lin (2020) de artan Covid-19 vakalarının toplumsal kaygı ve endişeleri arttırdığından bahsetmiştir. Nitekim salgının etkisinin azaltılmasına yönelik maske takma, sosyal mesafe, vücut 1sısını takip etme, uzaktan çalışma, ücretli izinleri uzatma, karantina süreçleri, sokağa çıkma yasakları gibi birçok uygulamalara yer verilmiştir. Bu uygulamaların dışında daha koruyucu ve önleyici tedbirler olan ve insan etkileşiminin fazla olduğu eğitim kurumları, restoranlar, sinemalar, müzeler, kütüphaneler, eğlence ve spor tesisleri gibi birçok yerlerin de salgin döneminde kapatıldığı görülmüsstür (Bozkurt vd., 2020, s. 12). Özellikle geniş bir kitleyi kapsayan ve etkileşimin yoğun olduğu eğitim alanında öncelikli olarak önlemler alınmış vakit kaybedilmeden uygulamaya konulmuştur. Bu sayede okulların eğitime ara verilmesi kararı dünyadaki öğrenci nüfusunun \%91'inden fazlasını etkisi altına almıştır (Miks ve McIlwaine, 2020).

Türkiye'de Milli Eğitim Bakanlığı (MEB) Covid-19 ile mücadelede diğer ülkelere göre daha hızlı tepki göstermiş ve okullar kapatılma sürecinden sonra hem internet üzerinden hem de internet erişiminde sıkıntı çeken öğrenciler için televizyon aracilı̆̆ıla uzaktan eğitim desteğini hemen hizmete sunmuştur. Aynı zamanda uzaktan eğitimde ihtiyaç duyulan ders içerikleri her kademe için hızla oluşturulmuş ve uzaktan eğitim platformlarına taşınmıştır (Özer, 2020a). Bu salgın döneminde 2012 yılında kurulan öğretmenöğrenci etkileşimine dayanan Eğitimde Bilişim Ağı (EBA) aktif bir şekilde kullanıma alınmış ve alt yapısı güçlendirilmiştir. EBA platformunun yanında ilkokul, ortaokul ve lise kademelerine yönelik EBA TV kanalları uzaktan eğitim sürecinde kullanılmıştır. Covid-19 salgınından etkilenen öğrencilerin bu dönemde ev ortamında sıkıldıkları, üzüldükleri, okullarını özledikleri ve akranlarıyla bir arada olamadıkları için depresyona girdikleri; okulların kapalı olmasından dolayı eğitimleri ile ilgili sorunlar yaşadıkları görülmekte ve bunların telafilerini aileleriyle yapmaya çalıştıkları görülmektedir (Organisation for Economic Cooperation and Development [OECD], 2020a; OECD 2020b). MEB bu süreçte öğrencilerin ve ailelerin psikolojik durumlarını da göz önünde bulundurarak onların psikolojik dayanıklıllğını desteklemek için yardım hattı oluşturarak ögrenci ve velilerin danışmanlarla telefonla doğrudan iletişim kurmalarını sağlamıştır (Özer, 2020b, s. 1128). Ayrıca öğretmenlerin de salgın döneminde öğrencileriyle iletişime geçerek onları sürece ilişkin bilgilendirmeleri ve rahatlatmaları, onların yanında olduğunun hissinin uyandırılması hem öğrencilerin kendilerini iyi hissetmelerine hem de motivasyonlarını yüksek tutmalarına katk1 sağlaması açısından önemli olduğu düşünülmektedir.

Özellikle ilkokul dönemindeki öğrencilerin, öğretmenlerinin yanlarında olduğunu hissetmeleri onların salgın sürecini kolay atlatmalarını sağlayabilir. Salgın döneminde yürütülen uzaktan eğitim sürecinin hem sınıf öğretmenlerini hem de ilkokul öğrencilerini önemli derecede etkilediği söylenebilir. Nitekim Ertan Kantos (2020) ilkokul öğrencilerinin somut işlemler dönemde olmalar1 ve kendi öğretmenlerinin ders anlatımlarına alışı olmaları, kendi başlarına ders çalışabilme disiplinine sahip olmamaları gibi sebeplerden dolayı farklı olumsuzluklarla karşılaşma ihtimalleri daha yüksek olduğunu dolayısıyla sınıf öğretmenlerinin uzaktan eğitimde öğrencileri için neler yaptıkları ya da neler yapamadıkları büyük önem kazandığını böylece sınıf öğretmenlerinin uzaktan eğitim sürecinde öğrencileri için yüz yüze eğitimden daha fazla bir çaba içerisinde olmalarını da gerekli kıldığını ifade etmiştir. Covid-19 salgın döneminde uzaktan eğitim sürecinde sınıf öğretmenleriyle ilgili yapılan çalışmaların (Ertan Kantos, 2020; Duban ve Şen, 2020; Yurtbakan ve Akylldı, 2020; Sönmez, Yıldırım ve Çetinkaya, 2020; Fidan, 2020) olduğu görülmektedir. Ancak sınıf öğretmenleriyle yapılan çalışmaların ilkokul döneminde okutulan herhangi bir dersle ilişkili yapılmadığ1 görülmüștür. Hayatın bilgisi olarak da ifade edilen Hayat Bilgisi dersi, (Tay, 2017) hem içeriği bakımından hem de öğrencilerin bu ders kapsamında öğrendiklerini yaşantısında sıkça kullanmasından dolayı salgının bu dersin öğretimi üzerindeki durumu incelenmiştir. Öğrencilerin günlük yaşantısıyla ilişkili 
öğrenmeler gerçekleştirmesi ve bunları yaşantısına aktarması, iyi ve sorumlu birer vatandaş olması, beceri eğitimi kazanması, bulunduğu toplumu benimsemesi ve uyum sağlaması gibi becerilerin kazandırldığg derslerin başında Hayat Bilgisi dersi gelmektedir (Y1lmaz ve Göçen, 2019, s.76). Dolayısıyla Covid-19 salgın süreciyle hayatımızda birçok değişikliğin yaşanması ve yeni bir sürecin başlamasından dolayı Hayat Bilgisi dersi üzerinde çalışmanın yapılması kararlaştırılmıştır. Bu sebeple Covid-19 salgın dönemi uzaktan eğitim sürecinde Hayat Bilgisi dersi öğretiminin durumunu tespit etmek için bu çalışma yürütülmüş̧ür. Yapılacak bu çalışma ile hem alanyazına katkı sağlayacağı hem de Covid-19 salgın dönemi uzaktan eğitim sürecinde Hayat Bilgisi dersi öğretimine yönelik yapılacak çalışmalara 1şık tutacağı düşünülmektedir. Bu araştırma, Covid-19 salgın dönemi uzaktan eğitim sürecinde sınıf öğretmenlerinin Hayat Bilgisi dersi öğretimine yönelik görüşlerinin incelemesi amacıyla yapılmıştır. Bu amaç doğrultusunda aşağıdaki sorulara cevap aranmıştır:

1. Sınıf öğretmenlerinin Covid-19 salgın dönemi uzaktan eğitim sürecinde kullandığ1 materyaller nelerdir?

2. Sınıf ögretmenlerinin Covid-19 salgın dönemi uzaktan eğitim sürecinde yaptıkları ölçmedeğerlendirme uygulamaları nelerdir?

3. Sınıf öğretmenleri Covid-19 salgin dönemi uzaktan eğitim sürecinde Hayat Bilgisi dersinin daha fazla önem kazandığını düşünüyor mu? Neden?

4. Sınıf öğretmenlerinin Covid-19 salgın dönemi uzaktan eğitim sürecinde Hayat Bilgisi dersi öğretiminde karşlaştı̆̆ sorunlar nelerdir?

5. Sınıf öğretmenleri Covid-19 salgin dönemi uzaktan eğitim sürecinde EBA TV'deki Hayat Bilgisi dersini takip ediyor mu? Eğer ediyorsa dersin verimliliği hakkında ne düşünüyor?

6. Sınıf öğretmenleri Covid-19 salgın dönemi uzaktan eğitim sürecinde Hayat Bilgisi dersi öğretimine yönelik canlı ders haricinde EBA platformunu kullandı mı? Eğer kullanıldıysa ne tür uygulamalar yapildi?

7. Sınıf öğretmenlerinin Covid-19 salgın dönemi uzaktan eğitim sürecine yönelik Hayat Bilgisi dersi kazanımları hakkındaki düşünceleri nelerdir?

\section{Yöntem}

\section{Araştırma Modeli}

Bu çalış̧ada nitel araştırma yöntemlerinden durum çalışması deseni kullanılmıştır. Durum çalışması, derin ve çeşitli bilgi kaynaklarından beslenerek araştırılan durum hakkında zengin bir şekilde açılayıcı bilgiler sunar. Ayrıca katılımcıların açıklamaları, görüssleri ve diğer veri kaynaklarından elde edilen bilgiler birleştirilerek çalışılan durum hakkında karar verilir (Hancock ve Algozzine, 2006, s. 33). Hagan (2006) durum çalışmasını, bir ya da birkaç açıklayıcı durumun nitel olarak derinlemesine araştırılması olarak tanımlamaktadır.

\section{Çalışma Grubu}

Araştırmanın çalışma grubunu, Yozgat ilinde görev yapan 19 sınıf öğretmeni oluşturmaktadır. Örneklem seçiminde amaçlı örnekleme çeşitlerinden ölçüt örnekleme yöntemi kullanılmıştır. Ölçüt örnekleme, araştırmacı tarafindan oluşturabilen veya daha önceden belirlenebilen bir dizi ölçütü karşılayan durumların çalışılması olarak ifade edilmektedir (Yıldırım ve Şimşek, 2016, s. 122). Bu çalışmada da uzaktan eğitim faaliyetlerini canlı ders yaparak yürüten ve merkezde görev yapan öğretmenlerle görüşme yapılması ölçüt olarak belirlenmiştir. Çalsşma grubuna ilişkin demografik bilgiler Tablo 1'de sunulmuştur.

Tablo 1. Calisma Grubuna Ilişkin Demografik Bilgiler

\begin{tabular}{llc}
\hline & & Frekans (f) \\
\hline \multirow{2}{*}{ Cinsiyet } & Erkek & 9 \\
& Kadın & 10 \\
\hline \multirow{2}{*}{ Eğitim Durumu } & Lisans & 15 \\
& Yüksek Lisans & 4 \\
\multirow{2}{*}{ Mesleki Deneyim } & $1-5$ yll & 3 \\
& $6-10 \mathrm{yll}$ & 7 \\
& $11-15$ yll & 4 \\
\hline
\end{tabular}


Tablo 1 incelendiğinde, çalışmaya katılan öğretmenlerin cinsiyete göre; 10'unun kadın, 9'unun erkek, eğitim durumuna göre ise 4'ünün yüksek lisans ve 15'inin de lisans mezunu olduğu görülmektedir. Öğretmenlerin mesleki deneyimleri ise 3 ile 20 yılları arasında yer almaktadır. Ayrıca öğretmenlerin 3’ü 1 5 y1l, 7'si 6 - 10 y1l, 4'ü 11 - 15 y1l, 5’i 16 - 20 y1l mesleki deneyime sahiptir.

\section{Verilerin Toplanması ve Analizi}

Araştırmanın verileri, yarı yapılandırılmış görüşme formu aracılığıyla toplanmıştır. Görüşme soruları hazırlanırken alanyazın taraması yapılmış ancak Covid-19 döneminde Hayat Bilgisi dersine yönelik yapılan herhangi bir çalışmaya rastlanılmadığ1 görülmüştür. Görüşme formundaki sorular, çalışma grubuna dahil edilmeyen sınıf öğretmenleriyle yapılan görüşmeler sonucunda araştırmacılar tarafından oluşturulmuştur. Hazırlanan bu görüşme formu için doktora eğitimini tamamlamış üç öğretim elemanından ve iki sınıf öğretmeninden uzman görüşü alınmış ve görüşme formundaki iki soru çıkarılarak görüşme formuna son hali verilmiştir. Daha sonra çalışma grubunda yer almayan iki sınıf öğretmeniyle pilot görüşmeler gerçekleştirilmiş ve görüşme formunda herhangi bir değişiklik yapılmamıştır. Çalışma grubu ile yapılan görüşmeler sonucunda veriler toplanmıştır. Öğretmenlerin büyük bir çoğunluğu ile sesli veya görüntülü görüşmeler gerçekleştirilmiş, beş öğretmenle de Covid-19 salgın dönemi hijyen kurallarına dikkat ederek yüz yüze görüşmeler yapılmıştır. Ayrıca verilerin toplanma sürecinde farklı sebeplerden dolayı görüşmeyi kabul etmeyen öğretmenlerden veriler mail aracılığıyla toplanmıştır. Mail aracılığıyla toplanan veriler için de öğretmenlerle iletişime geçilerek uygun oldukları bir zaman diliminde görüşme formunda yer alan sorulara verdikleri yanıtlar hakkında kısa bir görüşme gerçekleştirilmiştir. Çalışma kapsamında toplanan veriler, betimsel analiz kullanılarak analiz edilmiştir. Ekiz’e (2015) göre betimsel analiz, araştırma sürecinde kullanılan gözlem, görüşme veya belge gibi veri toplama araçlarında bulunan soru ya da konu temelinde analiz edilmesidir. Analiz sürecinde elde edilen veriler araştırmacılar tarafından ayrı ayrı analiz edilerek Miles ve Huberman'ın (1994) kodlama güvenirliği formülü kullanılmıştır. Bu güvenirlik, ortak kodların, ortak kodlar ile ortak kodlara uymayan kodların toplamına bölünmesinden sonra 100 ile çarpılmasıyla elde edilir (Miles ve Huberman, 1994, s. 64). Bu formüle göre, analiz sürecinde araştırmacilar arasındaki kodlama uyumunun \% 95 olduğu sonucuna ulaşılmıştır. Elde edilen bulgular, öğretmenlerin görüşme formunda yer alan sorulara verdikleri cevaplardan yapılan doğrudan alıntılarla desteklenmiştir. Çalışmaya katılan sınıf öğretmenleri Ö1, Ö2,...̈̈19 olarak kodlanmıştır.

\section{Bulgular}

Bu bölümde Covid-19 salgın döneminde sınıf öğretmenleri ile Hayat Bilgisi dersi öğretimine yönelik yapılan görüşmelerden elde edilen verilerin analiziyle ortaya çıkan bulgulara yer verilmiştir.

\section{Covid-19 salgin dönemi uzaktan eğitim sürecinde Hayat Bilgisi dersi öğretiminde kullanılan materyallere ilişkin görüşler}

Çalışmaya katılan öğretmenlere, Covid-19 salg1n dönemi uzaktan eğitim sürecinde Hayat Bilgisi dersi öğretiminde kullandıkları materyallerin ne olduğu sorulmuş, elde edilen verilerin analizinden ulaşılan bulgular Tablo 2'de sunulmuştur.

Tablo 2. Ögrretmenlerin Hayat Bilgisi dersi ögrretiminde kullandıklar materyallere iliskin görïsleri

\begin{tabular}{llc}
\hline Kullanilan Materyaller & Öğretmenler & (f) \\
\hline Ders kitab1 & Ö1, Ö2,Ö4,Ö5,Ö6,Ö8,Ö9,Ö12,Ö17, Ö18, Ö19 & 11 \\
Video ve animasyonlar & Ö3,Ö5,Ö6,Ö10,Ö11,Ö12,Ö14,Ö15, Ö18, Ö19 & 11 \\
Eğitim platformları (okulistik, EBA, morpa) & Ö1,Ö2,Ö3,Ö4,Ö6,Ö7,Ö9,Ö13, Ö14 & 9 \\
Görsel sunumlar & Ö3, Ö4,Ö5,Ö11,Ö13,Ö15,Ö17,Ö19 & 8 \\
İnternet aracilığ1yla paylaş1lan etkinlikler (eğitimhane, sosyal medya vb.) & Ö1,Ö2, Ö3,Ö5,Ö7,Ö10, Ö13 & 7 \\
Eğitici oyuncaklar & Ö5,Ö6,Ö14,Ö15 & 4 \\
Yardımc1 kaynaklar & Ö5,Ö8,Ö9 & 3 \\
Boyama etkinlikleri & Ö6 & 1 \\
Etkileşimli pdf ve Z-Kitap & Ö16 & 1 \\
\hline
\end{tabular}

Tablo 2'ye göre, öğretmenlerin Covid-19 salgin dönemi uzaktan eğitim sürecinde Hayat Bilgisi dersinde materyal olarak en çok ders kitabı ile video ve animasyonlardan yararlandıkları sonucuna ulaşılmıştır. Ayrıca öğretmenlerin EBA, okulistik ve morpa kampüs eğitim platformlarını (f=9), görsel sunumları $(\mathrm{f}=8)$, internet aracılığıyla paylaşılan etkinlikleri $(\mathrm{f}=7)$, eğitici oyuncakları $(\mathrm{f}=4)$ ve yardımc1 kaynakları $(\mathrm{f}=3)$ da materyal olarak kullandıkları görülmüştür. Öğretmenlerin boyama etkinlikleri $(\mathrm{f}=1)$ ile etkileşimli pdf ve Z-kitabı ( $f=1)$ salgın dönemi uzaktan eğitim sürecinde Hayat Bilgisi dersinde 
kullandıkları görülmüştür. Öğretmenlerin Hayat Bilgisi dersi öğretiminde kullandıkları materyallere ilişkin görüşlerinden bazıları şu şekildedir:

"Hocam salgmm olduğu bu dönemde de ders kitabm kullanyorum. Bunun dişnda konuy a göre okulistikten de faydalanmaya çalssyorum. Ayrca internetten arastırı bulduğumuz, etkinlikleri de kullanyorum. Eğitimhane gibi." (Ö1)

"Bu süreçte olabildig̈ince oynncaklardan, kuklalardan, resimlerden ya da online olarak yapilabilecek somut etkinlikler mesela konuyla ilgili videolar kullanyorum. Aynca tabi ders kitabımı̨ ve yardima kitaplarmız? da kullanyorum." (Ö5)

"Öncelikle eğitim sitelerinden okulistik, morpa gibi sitelerin ders anlatumlarndan faydalanyorum. Ders kitabl, kuklalar, boyama etkinlikleri ve ögrencilerimin cekmis olduklarn videolardan yararlanyorum. Simf arkadaşlarmm çekmis olduklar videolar daha çok ilgilerini çekiyor öğrencilerin.” (Ö6)

"Telefon, tablet veya bilgisayarlarda üzerinde işaretleme yapulabilen yažlar yazabileceği etkilleşimli pdf ve Zkitap çalssmalarm kullamyorum." (Ö16)

Covid-19 salgın dönemi uzaktan eğitim sürecinde Hayat Bilgisi dersi öğretimi ölçme değerlendirme sürecinde yapılan uygulamalara ilişkin görüşler

Çalışmaya katılan öğretmenlere, Covid-19 salgin dönemi uzaktan eğitim sürecinde Hayat Bilgisi dersi öğretimi ölçme değerlendirme sürecinde neler yaptıkları sorulmuş, elde edilen verilerin analizinden ulaşılan bulgular Tablo 3'de sunulmuştur.

Tablo 3. Öğretmenlerin Hayat Bilgisi dersi ögretimi ölgme değerlendirme sürecine ilişkin görüsleri

\begin{tabular}{llc}
\hline Ölçme değerlendirme süreci & Öğretmenler & (f) \\
\hline Soru cevap & Ö3,Ö4,Ö5,Ö6,Ö7,Ö9,Ö10,Ö12,Ö14,Ö15,Ö18 & 11 \\
Ders kitab1 etkinlikleri & Ö5,Ö8,Ö13,Ö14,Ö15,Ö17,Ö18,Ö19 & 8 \\
Ödev verme ve kontrol etme & Ö4,Ö5,Ö9,Ö11,Ö16 & 5 \\
İnternet aracillğ1yla paylaş1lan etkinlikler (eğitimhane, sosyal medya vb.) & Ö2,Ö3,Ö6,Ö11 & 4 \\
EBA'da etkinlik paylaşma & Ö10,Ö13,Ö14,Ö17 & 4 \\
Yardımc1 kaynak etkinlikleri & Ö5,Ö9,Ö19 & 3 \\
Eğitim platformu etkinlikleri (okulistik, morpa,) & Ö3,Ö19 & 2 \\
Öğrencilerin ders sürecine katılma durumu & Ö1,Ö4 & 2 \\
\hline
\end{tabular}

Tablo 3 incelendiğinde, salgin dönemi uzaktan eğitim sürecinde öğretmenlerin Hayat Bilgisi dersinde daha çok soru cevap $(\mathrm{f}=11)$ yöntemini kullanarak ölçme değerlendirmede bulunduklarını ifade etmişlerdir. Bunun dışında Hayat Bilgisi dersi öğretiminde öğretmenlerin ders kitabı etkinliklerini ( $f=8)$, ödev verme ve kontrol etmeyi $(\mathrm{f}=5)$, internet aracillğıyla paylaşılan etkinlikleri $(\mathrm{f}=4)$, EBA'da etkinlik paylaşımını $(\mathrm{f}=4)$, yardımc1 kaynak etkinliklerini ( $\mathrm{f}=3$ ), eğitim platformu etkinliklerini $(\mathrm{f}=2)$ ve öğrencilerin ders sürecine katılma durumunu $(\mathrm{f}=2)$ ölçme değerlendirme sürecinde kullandıkları görülmüştür. Bu konuda Ö3, Ö4 ve Ö19’un görüşleri şu şekildedir:

"Anlk yaynnlarda soru cevabr kullanyorum. Farkh olarak okulistik, morpa, eğitimbane değerlendirme sorularm kullanyorum." (Ö3)

"Ölçme ve değerlendirme sürecinde ögrencilerin derse kathlp katılmadlklarm gö̈lemliyorum. Derste sorular soruyorum ve verdig̈im ödevleri kontrol ediyorum. Bu șekilde hocam.” (Ö4).

"Farkh kaynaklardan, okulistikten, eğitim setlerinden işlediğimiz, konulara yönelik boşluk. doldurma,

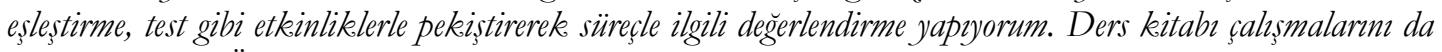
kullanyorum."(Ö19)

Covid-19 salgın dönemi uzaktan eğitim sürecinde Hayat Bilgisi dersinin daha fazla önem kazandığını düşünüp/düşünmemelerine ilişkin görüşler

Çalışmaya katılan öğretmenlere, Covid-19 salgın dönemi uzaktan eğitim sürecinde Hayat Bilgisi dersinin daha fazla önem kazandığını düşünüyor musunuz? Neden? sorusu sorulmuş, öğretmenlerin tamamının Hayat Bilgisi dersinin öneminin arttı̆̆ını düşündüğünü ifade etmiştir. Elde edilen verilerin analizinden ulaşılan bulgular Tablo 4'de sunulmuştur. 
Tablo 4. Öğretmenlerin Hayat Bilgisi dersinin daha fąla önem kazandiğın düs̆̈̈n̈̈p/ düsünmediklerine ilişkin görüsleri

\begin{tabular}{llc}
\hline Dersin daha fazla önem kazandığını düşünüyorum. & \multicolumn{1}{c}{ Öğretmenler } & (f) \\
Çünkü? & & 12 \\
\hline Dersin içeriğinde temizlik, kişisel bakımı̈ı olması & Ö1,Ö2,Ö3,Ö7,Ö11,Ö12,Ö13,Ö14,Ö15,Ö16,Ö18,Ö19 \\
Öğrenilenleri günlük hayatla ilişkilendirmeyi sağlaması & Ö3, Ö5,Ö6,Ö7,Ö9,Ö10,Ö13,Ö17 & 8 \\
Öğrencilerin kendini rahat ifade etmesi için ortam sağlamas1 & Ö3,Ö4,Ö6,Ö9,Ö10,Ö19 & 6 \\
Hayata yönelik bilgiler sunması & Ö4,Ö8,Ö10,Ö14 & 4 \\
Toplum sağllğına katk1 sunması & Ö3,Ö16, & 2 \\
Çevreyle iletişim kurmayı sağlaması & Ö1 & 1 \\
Sağllklı yaşama katk1 sunması & Ö17 & 1 \\
Gündelik konuların işlenmesi & Ö18 & 1 \\
\hline
\end{tabular}

Tablo 4 incelendiğinde, öğretmenler, dersin içeriğinde temizlik, kişisel bakımın olması $(\mathrm{f}=12)$, öğrenilenleri günlük hayatla ilişkilendirmeyi sağlaması $(\mathrm{f}=8)$, öğrencilerin kendini rahat ifade etmesi için ortam sağlaması $(\mathrm{f}=6)$, hayata yönelik bilgiler sunması $(\mathrm{f}=4)$ ve toplum sağlı̆̆ına katk1 sunması $(\mathrm{f}=2)$ açısından salgın döneminde Hayat Bilgisi dersinin önem kazandığını ifade etmişlerdir. Ayrıca çevreyle iletişim kurmayı sağlaması ( $\mathrm{f}=1$ ), sağlık yaşama katkı sunması ( $\mathrm{f}=1$ ) ve gündelik konuların işlenmesinden $(\mathrm{f}=1)$ dolayı da dersin öneminin arttığını düşündükleri görülmüştür. Konuyla ilgili öğretmen görüşlerinden bazıları şunlardır:

"Evet hocam düsünüyorum tabi. Hayat bilgisi dersindeki kişisel bakımın, temizlik kurallarnmn ne kadar önemli olduğunu ve bunu da hayatımızda kullanmamız̨n önemli bir şey olduğunu biliyorduk, tekerar kavramıs olduk bu süreçte." (Ö7)

"Evet düsünüyorum. Çünkü Hayat Bilgisi dersi ögrencilere aslında hayatın bilgisini sunuyor. Şuan salgın bir bastalı döneminden gectiğimiz için dersimizde buna yönelik temizlik ve bijyen konularna daba sik değiniyoruz:" (Ö14)

"Evet düsünüyorum hocam. Çünkü Hayat Bilgisi dersinde daha çok gündelik yaşantımızdaki konular isliyoruz. Bu salgm döneminde de bijjen ve temizlik konularma değindiğimiz için dersin önemi daha da arttı." (Ö18)

\section{Covid-19 salgın dönemi uzaktan eğitim sürecinde Hayat Bilgisi dersi öğretiminde karşılaşılan sorunlara ilişkin görüşler}

Çalışmaya katılan öğretmenlere, Covid-19 salg1n dönemi uzaktan eğitim sürecinde Hayat Bilgisi dersi öğretiminde karşılaştıkları sorunların neler olduğu sorulmuş, elde edilen verilerin analizinden ulaşılan bulgular Tablo 5'te sunulmuştur.

Tablo 5. Öğretmenlerin Hayat Bilgisi dersi ögretiminde karşılaştıklar sorunlara ilişkin görüsleri

\begin{tabular}{llc}
\hline Karşılaşılan sorunlar & Öğretmenler & (f) \\
\hline İnternet erişim olanaklarının yetersiz olmas1 & Ö6,Ö11,Ö14,Ö15,Ö16,Ö17,Ö18 & 7 \\
Somut materyaller kullanamama & Ö2,Ö3,Ö11,Ö12,Ö14,Ö16 & 6 \\
Öğrencilerin derse aktif katılamamas1 & Ö2,Ö3,Ö4,Ö9,Ö10 & 5 \\
Konuları canlandıramama & Ö1,Ö2,Ö9,Ö15,Ö16 & 5 \\
Sınıf ikliminin oluşmamas1 & Ö13,Ö14,Ö18,Ö19 & 4 \\
Ders saati süresinin k1sa olmas1 & Ö8,Ö10,Ö14,Ö19 & 4 \\
Sinıf dış1 etkinlikler yapamama & Ö3,Ö8,Ö16 & 3 \\
Etkinliklerin eğlenceli geçmemesi & Ö6,Ö14 & 2 \\
Velilerin öğrencilere derte yardım etmesi & Ö5 & 1 \\
Öğrencilerin ekrana bağımlı olmas1 & Ö7 & 1 \\
Ders kitab1 etkinliklerinin uzaktan eğitime uymamas1 & Ö17 & 1 \\
Kullanılan yöntem ve tekniğin az olması & Ö12 & 1 \\
\hline
\end{tabular}

Tablo 5'e göre, Covid-19 salg1n dönemi uzaktan eğitim sürecinde Hayat Bilgisi dersi öğretiminde öğretmenlerin; internet erişim olanaklarının yetersiz olması $(f=7)$, somut materyaller kullanamama $(f=6)$, ögrencilerin derse aktif katılamaması $(\mathrm{f}=5)$, konuları canlandıramama $(\mathrm{f}=5)$, sınıf ikliminin oluşmaması $(\mathrm{f}=4)$, ders saati süresinin kısa olması $(\mathrm{f}=4)$, sınıf dişı etkinlikler yapamama $(\mathrm{f}=3)$ ve etkinliklerin eğlenceli geçmemesi ( $f=2)$ sorunlarıyla karşılaştıkları görülmüştür. Ayrıca velilerin öğrencilere derste yardım etmesi $(\mathrm{f}=1)$, ögrencilerin ekrana bağımlı olması $(\mathrm{f}=1)$, ders kitabı etkinliklerinin uzaktan eğitime uymaması $(\mathrm{f}=1)$ ve kullanılan yöntem ve tekniğin az olması ( $\mathrm{f}=1$ ) sorunlarının da bu süreçte yaşandığı sonucuna ulaşılmıştır. Öğretmenlerle yapılan görüşmelerden bazıları şunlardır: 
"Bircok kazanm aslinda materyallerle destekleyip kazanmalarm sağhyoru₹: Öğrencilerin de derste sürece katılmast istediğim bir şey ve bu da uzaktan mümkün olmuyor. Tabi bu süreşte canlandirma da yapamyoruz, bence bu da önemli bir eksiklik." (Ö2)

"Bu sürecin benim için en büyülk sıkantıst, diğer derslerde olduğu gibi Hayat Bilgisi dersinde de tüm ögrencilerime ulasamamak. Ayrica bu dönemde uzaktan eğitimde yaptrŏgmız materyalleri de kullanamıyoruz, yani ögrenci ona dokunamiyor." (Ö11)

"Ders saatleri daba kısa olduğu için tüm ögrrencilerin fikir beyanlar mümkün olmuyor. Sımf dışında baž konularda yaptiğımı fizilesel etkinlikeleri yapamyyoruz:" (Ö8)

\section{Covid-19 salgın dönemi uzaktan eğitim sürecinde EBA TV'deki Hayat Bilgisi dersinin verimliliğine ilişkin görüşler}

Çalışmaya katılan öğretmenlere, Covid-19 salgın dönemi uzaktan eğitim sürecinde EBA TV'deki Hayat Bilgisi dersini takip ediyor musunuz? Ediyorsanız dersin verimliliği hakkında ne düşünüyorsunuz? Nedenleriyle açılar mısınız? sorusu sorulmuş, elde edilen verilerin analizinden ulaşılan bulgular Tablo 6'da sunulmuştur.

Tablo 6. Ögrretmenlerin EBA TV'deki Hayat Bilgisi dersini takip etmelerine/ etmemelerine ve dersin verimlilig̈ine iliskin görüsleri

\begin{tabular}{|c|c|c|c|}
\hline $\begin{array}{c}\text { EBA TV } \\
\text { takip durumu }\end{array}$ & \multicolumn{2}{|c|}{ EBA TV'nin verimlilik durumu ve nedeni } & \multirow{2}{*}{$\begin{array}{l}\text { (f) } \\
1\end{array}$} \\
\hline \multirow{15}{*}{$\begin{array}{l}\text { Takip } \\
\text { ediyorum }\end{array}$} & \multirow{5}{*}{$\begin{array}{l}\text { Verimli } \\
\text { buluyorum }\end{array}$} & İçeriğinin zevkli ve eğlenceli olması (Ö1) & \\
\hline & & Daha fazla öğrenciye ulaşması (Ö11) & 1 \\
\hline & & Konularla paralel ilerlemesi (Ö14) & 1 \\
\hline & & EBA canlı derslerin tekrarını sağlaması (Ö14) & 1 \\
\hline & & Etkili öğrenme süreci (Ö14) & 1 \\
\hline & \multirow{10}{*}{$\begin{array}{l}\text { Verimli } \\
\text { bulmuyorum }\end{array}$} & Öğrenci ve velinin EBA TV'yi takip etmemesi (Ö15, Ö16,Ö17,Ö18) & 4 \\
\hline & & Konuların yüzeysel olması (Ö4,Ö5,Ö19) & 3 \\
\hline & & Etkileşimin olmaması (Ö8,Ö12,Ö13) & 3 \\
\hline & & Değerlendirmenin eksik olması (Ö4, Ö12) & 2 \\
\hline & & Etkinliklerin eğlenceli olmaması (Ö5,Ö16) & 2 \\
\hline & & Öğretmen merkezli olması (Ö13) & 1 \\
\hline & & Kalıcı öğrenmelerin olmaması (Ö13) & 1 \\
\hline & & İlgi çekici materyal kullanmama (Ö16) & 1 \\
\hline & & Ekran başında çok vakit geçirme (Ö17) & 1 \\
\hline & & Konuların hızlı geçilmesi (Ö19) & 1 \\
\hline \multirow{2}{*}{$\begin{array}{l}\text { Kismen takip } \\
\text { ediyorum }\end{array}$} & \multirow{2}{*}{$\begin{array}{l}\text { Verimli } \\
\text { bulmuyorum }\end{array}$} & Etkileşimin olmamas1 (Ö2,Ö3,Ö6,Ö9,Ö10) & 5 \\
\hline & & Öğrenmenin yaparak yaşayarak olmaması (Ö7) & 1 \\
\hline
\end{tabular}

Tablo 6 incelendiğinde, Covid-19 salgin dönemi uzaktan eğitim sürecinde EBA TV'deki Hayat Bilgisi dersini öğretmenlerin 13'ünün takip ettiği, 6'sının ise kısmen takip ettiğgi sonucuna ulaşılmıştır. EBA TV'deki Hayat Bilgisi dersini takip eden öğretmenler, içeriğin zevkli ve eğlenceli olması ( $\mathrm{f}=1$ ), daha fazla ögrenciye ulaşması $(\mathrm{f}=1)$, konularla paralel ilerlemesi $(\mathrm{f}=1)$, EBA canlı derslerin tekrarını sağlaması $(\mathrm{f}=1)$ ve etkili öğrenme sürecinden ( $\mathrm{f}=1$ ) dolayı EBA TV'deki Hayat Bilgisi dersini verimli buldukları görülmüştür. Ancak öğretmenlerin; öğrencilerin ve velilerin EBA TV'yi takip etmemesi ( $\mathrm{f}=4)$, konuların yüzeysel olması $(\mathrm{f}=3)$, etkileşimin olmaması $(\mathrm{f}=3)$, değerlendirmenin eksik olması $(\mathrm{f}=2)$, etkinliklerin eğlenceli olmaması $(\mathrm{f}=2)$, öğretmen merkezli olması ve kalıcı öğrenmelerin olmaması $(\mathrm{f}=1)$, öğretmen de ilgi çekici materyal kullanmama ( $\mathrm{f}=1)$, ekran başında çok vakit geçirme $(\mathrm{f}=1)$ ve konuların hızlı geçilmesi sebepleriyle $(\mathrm{f}=1)$ EBA TV'deki Hayat Bilgisi dersini verimli bulmadıkları sonucuna ulaşılmıştır. Ayrıca kısmen takip ettiğini söyleyen 6 öğretmen ise, etkileşimin olmaması $(f=5)$ ve öğrenmenin yaparak yaşayarak olmamasından $(\mathrm{f}=1)$ dolayı verimli bulmadıkları görülmüsstür. Konuyla ilgili öğretmen görüşlerinden bazıları şunlardır:

"Takip ediyorum hocam, bence verimli. Cünkï canlı derslere katılamayan ögrencilerimiz oluyor ancak herkesin evinde televisyon olduğu için EBA TV'yi iəlevebiliyor, konular ögrenebiliyor." (Ö11)

"Takip ediyorum hocam, ancak ögrencilerde, ebeveynlerin birçoğunda TV'deki Hayat Bilgisi dersini ve diğer dersleri de iəleme sorumluluğu olmadiğg için TV'deki içeriklerin verimsiz olduğunu düs̆̈̈n̈̈yorum.” (Ö15) 
"Takip ediyorum hocam dersleri. Ders süresince konularn yüzeysel bir şekilde geçildiğini düsünüyorum. Ayruca derste anlatılanlarla ilgili değerlendirmenin eksike kaldı̆̆ın düs̆̈̈nüyorum. Ondan verimli olmadiğıı düs̆̈̈n̈̈yorum." (Ö4)

"Açıçasi sürekli takip etmiyorum, ara sura diyelim. Hayat Bilgisi dersi etkileşimli bir ders ancak karşllk.h etkileşim söz konusu olmadı̆̆ için EBA TV de, yeterince verimli ve etkili olduğunu düs̈̈̈nmüyorum.” (Ö9)

Covid-19 salgın dönemi uzaktan eğitim sürecinde Hayat Bilgisi dersi öğretimine yönelik EBA platformuna ilişkin görüşler

Çalışmaya katılan öğretmenlere, Covid-19 salgın dönemi uzaktan eğitim sürecinde Hayat Bilgisi dersi öğretimine yönelik canlı ders haricinde EBA platformunu kullandınız mı? Kullandıysanız ne tür uygulamalar yaptınız? Anlatır mısınız? soruları sorulmuş, elde edilen verilerin analizinden ulaşılan bulgular Tablo 7'de sunulmuştur.

Tablo 7. Öğretmenlerin Hayat Bilgisi dersi ögretimine yönelik canle ders haricinde EB A platformunu kullamip kullanmadıklarna ve yaptıklar uygulamalara ilişkin görüsleri

\begin{tabular}{llc}
\hline $\begin{array}{l}\text { EBA platformunu } \\
\text { kullanma durumu }\end{array}$ & Yapılan uygulamalar & (f) \\
\hline Kullandım & Etkinlik hazırlama, paylaşma (Ö3,Ö4,Ö5,Ö6,Ö9,Ö11,Ö12,Ö13,Ö14,Ö15, Ö16,Ö17) & 12 \\
& Video paylaşma (Ö3,Ö5,Ö6,Ö9,Ö10,Ö11,Ö12,Ö15,Ö19) & 9 \\
& Sinav hazırlama (Ö3,Ö10,Ö13,Ö14,Ö16,Ö19) & 6 \\
& Ödev verme (Ö4,Ö5,Ö9,Ö14,Ö16,Ö17) & 6 \\
& Öğrencilerin durumunu takip etme (Ö6,Ö13,Ö19) & 3 \\
& Tartışma yapma (Ö14,Ö15) & 2 \\
& Oylama yapma (Ö14,Ö15) & 2 \\
\hline Kullanmadım & Ö1,Ö2,Ö7,Ö8,Ö18 & 5 \\
\hline
\end{tabular}

Tablo 7’ye göre, Hayat Bilgisi dersi öğretimine yönelik canlı ders haricinde öğretmenlerin 14'ü EBA platformunu kullandığ1 5 öğretmenin ise bu platformu kullanmadığ1 sonucuna ulaşılmıştır. EBA platformunu kullanan öğretmenlerin en fazla etkinlik hazırlama, paylaşma ( $\mathrm{f}=12$ ) için en az ise tartışma ve oylama (f=2) yapmak için kullanıldığı görülmüştür. Ayrıca Covid-19 salgın dönemi uzaktan eğitim sürecinde öğretmenlerin; video paylaşma $(\mathrm{f}=9)$, sınav hazırlama $(\mathrm{f}=6)$, ödev verme ( $\mathrm{f}=6$ ), öğrencilerin durumunu takip etme $(\mathrm{f}=3)$ uygulamalarını yaptıkları görülmüştür. Bu konuda Ö12, Ö17 ve Ö18’un görüşleri şu şekildedir:

"Evet EBA platformunu kullandim, hala aktif bir sekilde kullanyorum. Etkinlikler haztrlyyorum ve kullanyorum. Ögrencileri birebir takip ediyorum. Faydalı ve güzel bir platform olduğunu düsünüyorum." (Ö6)

"Kullandım hocam. Etkinlik örneklerini hąırlyyorum, sonra onlar paylaşıyorum. Sağlıkla, temizllikle ilgili videolar paylaşzyorum.” (Ö12)

"Hocam ben elimden geldiğince kullanıyorum. İslediüim konularla ilgili hąırladı̆̆ım etkinlikleri paylaşıyorum. Ödev veriyorum. Bu sekilde kullanyorum.” (Ö17)

"EBA'da yeterli içeriklerin olmamasından dolayı kullanmıyorum." (Ö18)

Covid-19 salgın dönemi uzaktan eğitim sürecinde Hayat Bilgisi dersi kazanımlarına ilişkin görüşler

Çalışmaya katılan öğretmenlere, Covid-19 salg1n dönemi uzaktan eğitim sürecinde Hayat Bilgisi dersi kazanımları hakkındaki düşüncelerinin neler olduğu sorulmuş, elde edilen verilerin analizinden ulaşılan bulgular Tablo 8'de sunulmuştur.

Tablo 8. Ögretmenlerin Hayat Bilgisi dersi kazanmlarna iliskin görüsleri

\begin{tabular}{llc}
\hline Kazanımlara ilişkin görüşler & Öğretmenler & (f) \\
\hline Olağanüstü durumlara göre yenilenmeli & Ö5,Ö6,Ö12,Ö14,Ö16,Ö17,Ö18,Ö19 & 8 \\
Salgnnlara yönelik kazanımlar eklenmeli & Ö7,Ö9,Ö14,Ö15,Ö16,Ö17,Ö18,Ö19 & 8 \\
Sağl1klı bireyler yetisstirmeye uygun olması & Ö1,Ö4,Ö13,Ö15 & 4 \\
Geleceğe yönelik olmalı & Ö8,Ö10,Ö15,Ö18 & 4 \\
Günlük hayatta işlevsel olması & Ö2,Ö4,Ö8,Ö11 & 4 \\
Uzaktan eğitimle ilgili kazanımlar eklenmeli & Ö14,Ö16,Ö17 & 3 \\
Kazanım sayısı azaltılmalı & Ö3,Ö12 & 2 \\
Sağlığa yönelik kazanımlara ayrılan süre artmalı & Ö7 & 1 \\
\hline
\end{tabular}


Tablo 8'e göre Covid-19 salgın dönemi uzaktan eğitim sürecinde Hayat Bilgisi dersi kazanımlarına ilişkin öğretmen görüşleri incelendiğinde, öğretmenlerin önemli bir kısmı kazanımların olağanüstü durumlara göre yenilenmesi $(\mathrm{f}=8)$ ve salgınlara yönelik kazanımların eklenmesine $(\mathrm{f}=8)$ yönelik görüş belirtmișlerdir. Ayrıca öğretmenler kazanımlarla ilgili, sağlıklı bireyler yetiştirmeye uygun olması ( $\mathrm{f}=4$ ), geleceğe yönelik olması $(\mathrm{f}=4)$, günlük hayatta işlevsel olması $(\mathrm{f}=4)$ ve uzaktan eğitimle ilgili kazanımlar eklenmesine ( $\mathrm{f}=3$ ) yönelik görüşlerde bulunmuşlardır. 2 öğretmen salgın döneminde kazanım sayısının azaltılması gerektiğini ifade ederken 1 öğretmen de sağlığa yönelik kazanımlara ayrılan sürenin artması gerektiğini belirtmiştir. Öğretmenlerle yapılan görüşmelerden bazıları şunlardır:

"Genel olarak kazanmlar yeterli değgil bence. Cü̈nk̈̈ salgin hastalıklar hakekında bilgi sonra teknolojinin doğru kullanılmasina yönelik bilgiler, karşılaşılan sorunlar karşısında verilmesi gereken bilincin yeterli bir şekilde yer aldiğm düşünmüyorum. Mesela geçen sene ortaya çıkan salgin nedeniyle kitap içeriklerinin, kazammlarm güncellenmesi gerekiyordu bence. Uzaktan eğitime yönelik kazanmlar olabilir, konulara yer verilebilir" (Ö17)

"Hocam kazanumlar güncel konulara göre gelisțtirilebilirler. Özellikle bu tary salgmlarn gelecekte de artacăğ, ekolojik dengenin bozulacağz ön görülmekte. Bu sebeple bu konulara yönelik kazammlar eklenebilir.” (Ö18)

"Aslinda Hayat Bilgisi dersi programında temizlike ve bijyen konular bulunduğu için bu konulara dikkat eden bireyler yetisiyor aslinda. Ama gelecekte küresel olarak en çok yaşayacağımız problemler salgin bastaliklar olacaktır. Bu sebeple buna yönelik. kazanmmlar eklenmeli ve yoğun olarak işlenmelidir.” (Ö15)

\section{Tartışma, Sonuç ve Öneriler}

Çalışmaya katılan öğretmenlerin Covid-19 salgin dönemi uzaktan eğitim sürecinde Hayat Bilgisi dersi öğretiminde, ders kitabını, video ve animasyonları, eğitim platformlarını, görsel sunumları, internet aracılığıyla paylaşılan etkinlikleri, eğitici oyuncakları, yardımcı kaynakları, boyama etkinlikleri ile etkileşimli pdf ve Z-kitabını materyal olarak kullandıkları sonucuna ulaşılmıştır. Sönmez, Yıldırım ve Çetinkaya’nın (2020) çalışmasında öğretmenlerin çoğunluğunun salgın döneminde ek kaynaklardan faydalandıkları sonucuna ulaşılmışır. Ayrıca yapılan çalışmalarda (Bakioğlu ve Çevik, 2020; Sönmez, Yıldırım ve Çetinkaya, 2020) öğretmenlerin eğitim platformlarından biri olan EBA'yı bu süreçte etkin kullandıkları görülmüştür.

Covid-19 salgın dönemi uzaktan eğitim sürecinde Hayat Bilgisi dersi öğretiminde öğretmenlerin, soru cevabı, ders kitabı etkinliklerini, ödev verme ve kontrol etmeyi, internet aracilığılla paylaşılan etkinlikleri, EBA'da etkinlik paylaşımını, yardımcı kaynak etkinliklerini, eğitim platformu etkinliklerini ve öğrencilerin ders sürecine katılma durumunu ölçme değerlendirme sürecinde kullandıkları sonucuna ulaşılmıştır. Yurtbakan ve Akyıldız (2020) ile Bayburtlu'nun (2020) çalışmalarında ölçme değerlendirme kapsamında öğretmenlerin salgın dönemi süresince ödev vererek iletişime geçtikleri bulgularına ulaşılmıştır. Ancak Kalsen, Kaplan ve Şimşek (2020) ise, çalışmalarında öğrencilere ödev verilmesini doğru bulmadıklarını ifade etmişlerdir. Öğrencilerinin tamamının konuyu anlayıp anlamadıklarının o an görülmesi açısından öğretmenlerin Hayat Bilgisi dersinde soru cevap yöntemine daha çok yer verdiği söylenebilir. Hayat Bilgisi dersinde öğrencilerin ön bilgilerinden ve yaşantılarından kaynaklı bilgilerin çok olması ders sürecine etkin katılmaları da öğretmenler tarafindan ölçme değerlendirme sürecinde dikkate alındığı söylenebilir.

Covid-19 salgın dönemi uzaktan eğitim sürecinde öğretmenlerin tamamı Hayat Bilgisi dersinin öneminin daha da arttığını düşündükleri sonucuna ulaşılmıştır. Dersin içeriğinde temizlik, kişisel bakımın olması, öğrenilenleri günlük hayatla ilişkilendirmeyi sağlaması, öğrencilerin kendini rahat ifade etmesi için ortam sağlaması, hayata yönelik bilgiler sunma, toplum sağlı̆̆ına katkı sunması, çevreyle iletişim kurmayı sağlaması, sağlık yaşama katkı sunması ve gündelik konuların işlenmesi açısından Hayat Bilgisi dersinin öneminin salgın döneminde arttı̆̆ öğretmenler tarafindan ifade edilmiştir. Hayat Bilgisi dersi, hayatın bilgisini sunan (Tay, 2017) bir ders olduğundan sadece salgin, felaket vb. durumlarda değil her zaman hayati bir önem taşımaktadır. Ancak Covid-19 salgın döneminde insanların yaşantılarında meydana gelen birçok değişiklik bundan sonraki yaşamlarına da etki edeceğinden Hayat Bilgisi dersinin öneminin daha da artacağ1 söylenebilir.

Öğretmenlerin Covid-19 salgin dönemi uzaktan eğitim sürecinde Hayat Bilgisi dersi öğretiminde; internet erişim olanaklarının yetersiz olması, somut materyaller kullanılamama, öğrencilerin derse aktif katılamaması, konuları canlandıramama, sınıf ikliminin oluşmaması, ders saati süresinin kısa olması, sınıf dışı etkinlikler yapamama, etkinliklerin eğlenceli geçmemesi, velilerin öğrencilere derste yardım etmesi, 
öğrencilerin ekrana bağımlı olması, kullanılan yöntem ve tekniğin az olması ile ders kitabı etkinliklerinin uzaktan eğitime uymaması sorunlarılla karşılaştıkları sonucuna ulaşılmıştır. Yapılan birçok çalışmada (Burke ve Dempsey, 2020; Bayburtlu, 2020; Fidan, 2020; Bakioğlu ve Çevik, 2020; Yolcu, 2020; Ertan Kantos, 2020; Sar1 ve Nayir, 2020; Baek, Jones, Bulger ve Taliaferro, 2018; Özyürek ve Bedge, 2016) internet erişiminden kaynaklı sorunların yaşandığı ortaya çıkmıştır. Yurtbakan ve Akyıldız'in (2020) araştırmasında da, ders süresinin kısa olduğunun ve öğrencilerin etkileşim ile eğlenceli etkinliklerin olmasından dolayı yüz yüze okulu tercih ettikleri bulgusuna ulaşılmıştır. Öğrencilerin somut dönemde olmalarından dolayı Hayat Bilgisi dersinin daha fazla somutlaştırılarak işlenmesi gerektiği ancak uzaktan eğitimde somut materyallerin kullanılamaması, öğrencilerin derse aktif katılamaması, konuların canlandırılamaması gibi sorunların ortaya çıkmasından dolayı Hayat Bilgisi dersi konularının öğrenilmesinde problemlerle karşılaşabileceği söylenebilir.

Covid-19 salgın dönemi uzaktan eğitim sürecinde öğretmenlerin önemli bir kısmı EBA TV'deki Hayat Bilgisi dersini takip ettiği ancak azımsanmayacak kadar öğretmenin ise takip etmediği görülmüştür. EBA TV'deki Hayat Bilgisi dersini takip eden öğretmenlerin, içeriğin zevkli ve eğlenceli olması, daha fazla öğrenciye ulaşması, konularla paralel ilerlemesi, EBA canlı derslerin tekrarını sağlaması ve etkili öğrenme sürecinden dolayı verimli bulduğu görülmüştür. Ayrıca takip eden öğretmenlerin de öğrenci ve velinin EBA TV'yi takip etmemesi, konuların yüzeysel olması, etkileşimin olmaması, değerlendirmenin eksik olmas1, etkinliklerin eğlenceli olmamas1, öğretmen merkezli olması, kalıc1 öğrenmelerin olmaması, ilgi çekici materyal kullanılmaması, ekran başında çok vakit geçirilmesi ve konuların hızlı geçilmesi sebepleriyle EBA TV'deki Hayat Bilgisi dersini verimli bulmadıkları sonucuna ulaşılmıştır. Kısmen takip ettiğini söyleyen öğretmenlerin ise etkileşimin olmaması ve öğrenmenin yaparak yaşayarak olmamasından dolayı verimli bulmadıkları görülmüştür. Baturay ve Yükseltürk (2015) uzaktan eğitimde derslerin tekrarının sağlanmasının öğrencilerin akademik başarılarına olumlu yansıdığından bahsetmektedir. Yurtbakan ve Akyıldız (2020) çalışmalarında öğretmenlerin, Covid-19 izolasyon döneminde uzaktan eğitimi konuların yüzeysel anlatılması ve öğrenci öğretmen etkileşimi kurulamamasından dolayı yetersiz buldukları sonucuna ulaşmışlardır. Sönmez, Yıldırım ve Çetinkaya (2020) çalışmalarında da sınıf öğretmenlerinin EBA TV'deki ders anlatımlarını hızlı bulduğu, ders tekrarlarının süreci olumsuz etkilediği ve dönüt sağlanamaması sonucuna ulaşılmıştır. Ayrıca öğretmenlerin büyük çoğunluğu EBA TV derslerini tek başına yeterli bulmadıklarını belirtmişlerdir. Öğretmenlerin yarısından fazlasının EBA TV'yi takip etmesine rağmen verimli bulmamalarında çoğunlukla EBA TV'nin hızlı bir şekilde kurulup hizmet vermeye başlamasındaki eksikliklerden ve uzaktan eğitimin getirdiği sorunlardan kaynaklandığ söylenebilir.

Hayat Bilgisi dersi öğretimine yönelik canlı ders haricinde öğretmenlerin büyük çoğunluğu EBA platformunu etkinlik hazırlamak, paylaşmak, video paylaşmak, sınav hazırlamak, ödev vermek, öğrencilerin durumunu takip etmek, tartısma ve oylama yapmak için kullandıklarını belirtmişlerdir. Öğretmenlerin bir kısmı ise EBA platformunu kullanmadıklarını ifade etmişlerdir. Sınıf öğretmenlerinin önemli bir kısmının EBA'y1 kullandığ1 ve en çok kullanılan derslerden birinin de Hayat Bilgisi dersi olduğu sonucuna ulaşılmıştır (Kurtdede Fidan, Erbasan ve Kolsuz, 2016). Tüysüz ve Çümen'in (2016) çalışmasında EBA platformunun konuların pekiştirilmesi, ödev yapma, sınavlara hazırlık vb. durumlarda faydalı bir site olduğuna yönelik bulgulara rastlamıştır. Çiftçi ve Aydın'ın (2020) çalışmasında da öğretmenlerin EBA üzerinden öğrencilerini ödevlendirdikleri sonucuna ulaşılmışır. Öğretmenlerin Covid-19 salgınında Hayat Bilgisi öğretiminde EBA platformunu daha çok değerlendirme sürecinde kullandıkları söylenebilir.

Covid-19 salgın dönemi uzaktan eğitim sürecinde Hayat Bilgisi dersi kazanımlarına ilişkin ögretmenler, kazanımların olağanüstü durumlara göre yenilenmesi, salgınlara yönelik kazanımların eklenmesi, sağlıklı bireyler yetiştirmeye uygun olması, geleceğe yönelik olması, günlük hayatta işlevsel olması ve uzaktan eğitimle ilgili kazanımların eklenmesi gerektiğine yönelik görüşler belirtmişlerdir. Ayrıca salgın döneminde kazanım sayısının azaltılması ve sağlığa yönelik kazanımlara ayrılan sürenin de artması gerektiğini ifade etmişlerdir. Yurtbakan ve Akyıldız'ın (2020) araştırmasında, salgın döneminde kazanımlara ayrılan ders süresinin yetersiz olduğu bulgusuna ulaşılmıştır. Öğretmenlerin Hayat Bilgisi dersi kazanımları temizlik, kişisel bakım, günlük hayatla ilişkilendirme, hayata yönelik bilgiler sunma, toplum sağlığı, çevreyle iletişim, sağlıklı yaşam, gündelik konuların işlenmesi açısından önemli görülürken kazanımların olağanüstü durumlara göre yenilenmesi, salgınlara yönelik kazanımların eklenmesi, geleceğe yönelik kazanımların olması gibi sebeplerden dolayı da Hayat Bilgisi dersi kazanımlanının gözden geçirilmesinin önemli olduğu söylenebilir. 


\section{Öneriler}

- Covid-19 salgin dönemi uzaktan eğitim sürecine yönelik ilkokul düzeyinde farklı derslere yönelik çalışmalar yapılabilir.

- Salgın dönemi uzaktan eğitim sürecinde sınıf öğretmenlerinin yaptıkları uygulamalara ilişkin tarama çalışmaları yapılabilir.

- Hayat Bilgisi dersi kazanımlarının salgın, felaket vb. durumlar karşısında ihtiyacı karşılayıp karşılamama durumunun incelendiği araştırmalar yapılabilir.

- Öğretmenlerle EBA platformunu değerlendirme sürecine yönelik çalışmalar dışında farklı derslere yönelik içerik oluşturma çalışmaları yapılabilir.

- EBA TV'deki öğrenme öğretme süreçleriyle ilgili başka ne tür etkinliklerin ve ilgi çekici materyallerin kullanılabileceğine yönelik çalışmalar yapılabilir.

\section{Etik Beyan}

"Covid-19 Salgın Döneminde Smif Ögretmenlerinin Hayat Bilgisi Dersi Öğretimine Yönelik Görüsleri” başlıklı çalışmanın yazım sürecinde bilimsel kurallara, etik ve alıntı kurallarına uyulmuş; toplanan veriler üzerinde herhangi bir tahrifat yapılmamış ve bu çalışma herhangi başka bir akademik yayın ortamına değerlendirme için gönderilmemiştir. Gerekli olan etik kurul izinleri Yozgat Bozok Üniversitesi Etik Komisyonu'nun 16.12.2020 tarih ve 16/25 sayılı kararı ile alınmıştır.

\section{Kaynakça}

Baek, J. H., Jones, E., Bulger, S., ve Taliaferro, A. (2018). Physical education teacher perceptions of technologyrelated learning experiences: A qualitative investigation. Journal of Teaching in Physical Education, 37(2), 175-185.

Bakioğlu, B. ve Çevik, M. (2020). COVID-19 pandemisi sürecinde fen bilimleri öğretmenlerinin uzaktan eğitime ilişkin görüssleri. Turkish Studies, 15(4), 109-129. https://dx.doi.org/10.7827/TurkishStudies.43502

Baturay, M. H. ve Yükseltürk, E. (2015). The role of online education preferences on student's achievement. The Turkish Online Journal of Distance Education, 16(3), 3-12. doi:10.17718/tojde.47810

Bayburtlu, Y. S. (2020). Covid-19 pandemi dönemi uzaktan eğitim sürecinde öğretmen görüşlerine göre Türkçe eğitimi. Turkish Studies, 15(4), 131-151.https://dx.doi.org/10.7827/TurkishStudies.44460

Bozkurt, A., Jung, I., Xiao, J., Vladimirschi, V., Schuwer, R., Egorov, G., ... ve Rodes, V. (2020). A global outlook to the interruption of education due to COVID-19 pandemic: Navigating in a time of uncertainty and crisis. Asian Journal of Distance Education, 15(1), 1-126.

Burke, J. ve Dempsey, M. (2020). Covid-19 practice in primary schools in Ireland report. Maynooth, Ireland.

Çiftçi, B. ve Aydın, A. (2020). Eğitim Bilişim Ağı (EBA) platformu hakkında fen bilimleri ögretmenlerinin görüşleri. Turkize Kimya Dernegi Dergisi Kısim C: Kimya Egitimi, 5(2), 111-130.

Duban, N. ve Şen, F. G. (2020). Sınıf öğretmeni adaylarının COVID-19 pandemi sürecine ilişkin görüşleri. Turkish Studies, 15(4), 357-376. https://dx.doi.org/10.7827/TurkishStudies.43653

Ekiz, D. (2015). Bilimsel Araştrma Yöntemleri. Ankara: Anı Yayınları.

Ertan Kantos, Z. (2020). Sinıf öğretmenlerinin uzaktan eğitim ile ilgili düşünceleri. 8. Uluslararası Bilimsel Araştırmalar Kongresi, Sosyal ve Egitim Bilimleri, 67-81.

Fidan, M. (2020). Covid-19 belirsizliğinde eğitim: İlkokulda zorunlu uzaktan eğitime ilişkin öğretmen görüşleri. Ușak Üniversitesi Eğitim Arasttrmalar Dergisi, 6(2), 24-43.

Hagan, F. E. (2006). Research methods in criminal justice and criminology. Boston: Allyn and Bacon.

Hancock, D.R. ve Algonzzine, B. (2006). A practical guide for beginning researchers doing case study research. New York: Teachers College Press.

Kalsen, C., Kaplan, İ. ve Şimşek, M. (2020). İlkokullardaki ev ödevlerine ilişkin yönetici, ögretmen ve veli görüşleri. Abant İzet Baysal Üniversitesi Eg̈itim Fakültesi Dergisi, 20(1), 527-547.

Kurtdede Fidan, N., Erbasan, Ö. ve Kolsuz, S. (2016). Sınıf öğretmenlerinin Eğitim Bilişim Ağı’ndan (EBA) yararlanmaya ilişkin görüşleri. Uluslararası Sosyal Araşstrmalar Dergisi, 9(45), 626-637.

Lin, C. Y. (2020). Social reaction toward the 2019 novel coronavirus (COVID-19). Social Health Behaviour, 3, 1-2.

Miks, J. ve Mcllwaine, J. (2020). Keeping the world's children learning through COVID-19. UNICEF.

Miles, M. B. ve Huberman, A. M. (1994). Qualitative data analysis. Sage Publications.

Organisation for Economic Co-operation and Development (OECD). (2020a). Learning remotely when schools close: How well are students and schools prepared? Insights from PIS A. 
Organisation for Economic Co-operation and Development (OECD). (2020b). Combatting COVID-19's effect on children.

Özer, M. (2020a). COVID-19 salgını sonrası dünyada eğitim. https://www.meb.gov.tr/covid-19-salgini-sonrasidunyada-egitim/haber/20936/tr adresinden alınmıştır.

Özer, M. (2020b). Türkiye'de COVID-19 salgını sürecinde Milli Eğitim Bakanlığı tarafından atılan politika adımları. Kastamonu Education Journal, 28(3), 1124-1129. https://dx.doi.org/10.24106/kefdergi.722280

Özyürek, A. ve Begde, Z. (2016). Uzaktan eğitim uygulamasının öğrenci bakış açısına göre değerlendirilmesi. Karabük Üniversitesi Sosyal Bilimler Enstitüsü Dergisi, 6(2), 592-605.

Sağlık Bakanlığı. (2020). Covıd-19 (Sars-Cov-2 Enfeksiyonu) genel bilgiler, epidemioloji ve tanı.

Sar1, T. ve Nayır, F. (2020). Pandemi dönemi eğitim: sorunlar ve firsatlar. Turkish Studies, 15(4), 959-975. https://dx.doi.org/10.7827/TurkishStudies.44335

Sönmez, M., Yıldırım, K. ve Çetinkaya, F. Ç. (2020). Yeni tip Koronavirüs (SARS-CoV2) salgınına bağlı uzaktan eğitim sürecinin sınıf öğretmenlerinin görüşleriyle değerlendirilmesi. Turkish Studies, 15(6), 855-875. https://dx.doi.org/10.7827/TurkishStudies.43799

Tüysüz, C. ve Çümen, V. (2016). EBA ders web sitesine ilişkin ortaokul öğrencilerinin görüşleri. Uşak Üniversitesi Sosyal Bilimler Dergisi, $9(27 / 3), 278-296$.

Yıldırım, A. ve Şimşek, H. (2016). Sosyal bilimlerde nitel araștırma yöntemleri. Ankara: Seçkin Yayınları.

Yılmaz, F., ve Göçen, S. (2019). Hayat bilgisi öğretimine ilişkin yapılan araştırmalara yönelik bir inceleme. Medeniyet Ë̆itim Araștirmalar Dergisi, 3(2), 76-86.

Yolcu, H. H. (2020). Sınıf öğretmeni adaylarının uzaktan eğitim deneyimleri. Açıkögretim Uygulamalar ve Araştırmalar Dergisi, 6(4), 237-250.

Yurtbakan, E. ve Akyıldız, S. (2020). Sınıf öğretmenleri, ilkokul öğrencileri ve ebeveynlerin Covid-19 izolasyon döneminde uygulanan uzaktan eğitim faaliyetleri hakkındaki görüşleri. Turkish Studies, 15(6), 949-977. https://dx.doi.org/10.7827/TurkishStudies.43780

Tay, B. (Edt.) (2017). Etkinlik örnekleriyle hayat bilgisi öğretimi. Ankara: Pegem Yayıncılık.

Türk Dil Kurumu, (2019). Online Türkçe sözlük.

World Health Organization (WHO). (2020). Coronavirus disease (COVID-19) Pandemic. World health Organization.

\section{EXTENDED ABSTRACT}

Since the world has existed, people have had to struggle with some disasters in certain periods until this time. These disasters have sometimes manifested themselves as a war, a natural disaster, a contagious disease. Today, this disaster has emerged as an epidemic and has affected the whole world. New Type Coronavirus (Covid-19), which emerged in Wuhan, China in December 2019, spread all over the world in a short time and was named as an epidemic by the World Health Organization (WHO, 2020). Considering the psychological conditions of the students and their families in this process, MoNE created a help line to support their psychological resilience and enabled students and parents to communicate directly with counselors by phone (Özer, 2020b, p.1128). In addition, it can be said that it is important for teachers to communicate with their students during the epidemic and inform them about the process, to relieve them, and to awaken the feeling of being with them, in terms of both making them feel good and keeping their motivation high.

During the Covid-19 epidemic period, it is seen that the studies on primary school teachers during the distance education process (Ertan Kantos, 2020; Duban and Şen, 2020; Yurtbakan and Akyldız, 2020; Sönmez, Yıldırım and Çetinkaya, 2020; Fidan, 2020) are limited. In addition, it was observed that studies conducted with primary school teachers did not correlate with any courses taught during the primary school period. This study was conducted to determine the status of the Life Science course teaching during the Covid-19 epidemic period.

This research was conducted in order to examine the opinions of primary school teachers regarding the Life Studies course teaching during the Covid-19 epidemic period. In this study, one of the qualitative research methods, case study design was used. The study group of the research consists of 19 primary school teachers working in Yozgat. Criterion sampling method, one of the purposeful sampling types, was used in sample selection. The research data were collected through a semi-structured interview form. Collected data were analyzed using descriptive analysis.

During the Covid-19 epidemic period of distance education, the teachers participating in the study used the Life Science course teaching, the textbook, videos and animations, educational platforms, visual presentations, activities shared on the internet, educational toys, auxiliary resources, painting activities and interactive pdf and Z-book as materials. They stated that they used. 
During the Covid-19 epidemic period of distance education, it was concluded that teachers used question-answer, textbook activities, assign and control homework, activities shared on the internet, share activities in EBA, auxiliary resource activities, educational platform activities and students' participation in the course process in the assessment and evaluation process.

All of the teachers came to the conclusion that they think the importance of the Life Science course has increased even more in the distance education process during the Covid-19 epidemic period. It was stated by the teachers that the importance of the Life Studies course increased during the epidemic period in terms of cleaning, having personal care, associating the learned with daily life, expressing oneself comfortably by students, providing information about life, public health, communication with the environment, health life and daily issues.

During the Covid-19 epidemic period, the distance education of teachers during the Life Science course teaching; Inadequate internet access facilities, inability to use concrete materials, students' inability to actively participate in the course, not being able to enliven the subjects, the classroom climate is not formed, the course time is short, the activities are not fun, the parents help the students in the course, the students are dependent on the screen, the method used and with the lack of technique, it was concluded that the textbook activities were not compatible with distance education.

During the Covid-19 epidemic period, it was observed that a significant number of teachers followed the Life Science course on EBA TV, but not too many teachers did not. It has been observed that the teachers who follow the Life Studies course on EBA TV find it productive because the content is enjoyable and entertaining, reaches more students, progresses in parallel with the subjects, ensures the repetition of EBA live courses and effective learning process. In addition, the teachers who follow do not follow the EBA TV, the subjects are superficial, there is no interaction, the evaluation is lacking, the activities are not fun, the teacher-centered, the lack of permanent learning, not using interesting materials, spending a lot of time in front of the screen and the subjects. It was concluded that they did not find the Life Studies course on EBA TV efficient due to the rapid passing. Teachers who said that they followed partially did not find it efficient due to the lack of interaction and learning by doing and living. Baturay and Yükseltürk (2015) mention that repeating courses in distance education has a positive effect on students' academic success.

Apart from the live course for the Life Studies course teaching, most of the teachers stated that they used the EBA platform to prepare activities, share videos, prepare exams, assign homework, follow up the status of students, discuss and vote. Some of the teachers stated that they do not use the EBA platform. It was concluded that a significant number of primary school teachers used EBA and one of the most used courses was the Life Studies course (Kurtdede Fidan, Erbasan and Kolsuz, 2016).

In the Covid-19 epidemic period, the teachers regarding the Life Science course acquisitions in the distance education process stated that the gains should be renewed according to extraordinary situations, the gains for the epidemic should be renewed, it should be suitable for raising healthy individuals, it should be for the future, it should be functional in daily life and the acquisitions related to distance education should be added. . They also stated that during the epidemic period, the number of gains should be reduced and the time allocated to health gains should also increase. 